\title{
DISCLOSURE VOLUNTÁRIO DAS INFORMAÇÕES AMBIENTAIS: ESTUDO DA RELAÇÃO ENTRE O NÍVEL DE EVIDENCIAÇÃO E O INVESTIMENTO AMBIENTAL NOS PAÍSES DO BRICS
}

\author{
VOLUNTARY DISCLOSURE OF ENVIRONMENTAL INFORMATION: A STUDY OF THE RELATIONSHIP \\ BETWEEN LEVEL OF DISCLOSURE AND ENVIRONMENTAL INVESTMENT IN THE BRICS COUNTRIES
}

DISCLOSURE VOLUNTARIO DE LAS INFORMACIONES AMBIENTALES: ESTUDIO DE LA RELACIÓN ENTRE EL NIVEL DE EVIDENCIACIÓN Y LA INVERSIÓN AMBIENTAL EN LOS PAÍSES DEL BRICS

\author{
ALAN DIÓGENES GÓIS \\ Doutorando \\ Universidade de São Paulo - Brasil \\ alandgois@hotmail.com
}

JOSÉ GLAUBER CAVALCANTE DOS SANTOS

Mestrando

Universidade Federal do Ceará - Brasil

jglauber_cont@hotmail.com

AUGUSTO CÉZAR DE AQUINO CABRAL

Doutor

Universidade Federal do Ceará - Brasil

cabral@ufc.br

MARIA NAÍULA MONTEIRO PESSOA

Doutor

Universidade Federal do Ceará - Brasil

naiula@ufc.br

Submetido em: 05/02/2014

Aprovado em: 28/07/2015

Doi: alcance.v22n4.p518-537

\section{RESUMO}

Este estudo objetiva determinar a relação entre o nível de evidenciação de informações voluntárias ambientais e o investimento ambiental nas empresas de capital aberto do BRICS. A pesquisa é descritiva com abordagem quantitativa, utilizando-se teste de diferença de média e regressão linear múltipla. Foram analisados os dados de 82 empresas de capital aberto que publicaram seus relatórios de sustentabilidade de 2011 no modelo GRI (3.0). Os resultados indicam que: (i) o nível de evidenciação ambiental no BRICS é de $59 \%$ para divulgação total e de $66 \%$ para essencial e que o nível de evidenciação de investimentos ambientais no BRICS foi de $51 \%$, sendo a Índia o país com melhores resultados; (ii) nas empresas com investimento ambiental, a divulgação ambiental (total e essencial) apresentou média superior àquelas que não possuíam investimento; (iii) o investimento ambiental mostrou-se impactante, positivamente, no nível de divulgação ambiental (total e essencial) do BRICS, assim como o tamanho, contudo o país (IDH) influencia negativamente o disclosure ambiental (total e essencial), já o impacto ambiental do setor apresentou relação positiva com o disclosure ambiental essencial. Portanto, 0 estudo não rejeita as hipóteses levantadas, demonstrando que o investimento ambiental é um fator decisivo na evidenciação ambiental no BRICS.

Palavras-chave: Disclosure ambiental. Investimento Ambiental. BRICS. 


\section{ABSTRACT}

This study aims to determine the relationship between the level of voluntary disclosure of environmental information and environmental investment in public companies of the BRICS countries. The research is descriptive with a quantitative approach, using the test of mean difference and multiple linear regression. Data from 82 public companies that published their sustainability reports in 2011 in the GRI (3.0) model were analyzed. The results indicate that: (i) the level of environmental disclosure in BRICS is $59 \%$ for total disclosure and $66 \%$ for core disclosure, and the level of disclosure of environmental investment in BRICS was $51 \%$, India being the country with the best results; (ii) in companies with environmental investment, environmental disclosure (total and core) had higher means than those with no investment; (iii) environmental investment proved to be having a positive impact on the level of environmental disclosure (total and core) of BRICS as well as the size. However, country (IDH) had a negative influence on environmental disclosure (total and core). Furthermore, the environmental impact of the sector showed a positive relationship with the core environmental disclosure. Therefore, the study does not reject the hypothesis suggested, demonstrating that environmental investment is a decisive factor of environmental disclosure within the BRICS.

Keywords: Environmental disclosure. Environmental investment. BRICS.

\section{RESUMEN}

Este estudio tiene el objetivo de determinar la relación entre el nivel de evidenciación de informaciones voluntarias ambientales y la inversión ambiental en las empresas de capital abierto del BRICS. La investigación es descriptiva con un enfoque cuantitativo y utiliza la prueba de diferencia de medias y regresión lineal múltiple. Se analizaron los datos de 82 empresas de capital abierto que publicaron sus informes de sostenibilidad de 2011 siguiendo el modelo GRI (3.0). Los resultados indican que: (i) el nivel de evidenciación ambiental en el BRICS es del $59 \%$ para la divulgación total y del $66 \%$ para la esencial y que el nivel de evidenciación de inversiones ambientales en el BRICS fue del $51 \%$, siendo la India el país con mejores resultados; (ii) en las empresas con inversión ambiental, la divulgación ambiental (total y esencial) presentó media superior a la de aquellas que no poseían inversión; (iii) la inversión ambiental se mostró impactante en sentido positivo a nivel de divulgación ambiental (total y esencial) del BRICS, así como el tamaño, aunque el país (IDH) influencia negativamente el disclosure ambiental (total y esencial); el impacto ambiental del sector, sin embargo, presentó relación positiva con el disclosure ambiental esencial. En consecuencia, el estudio no rechaza las hipótesis levantadas, demostrando que la inversión ambiental es un factor decisivo en la evidenciación ambiental en el BRICS.

Palabras clave: Disclosure ambiental. Inversión Ambiental. BRICS.

\section{INTRODUÇÃO}

As últimas décadas do século XX mostraram que o mundo passou por alterações relevantes no que tange ao modo de pensar a responsabilidade socioambiental nas organizações (FONSECA; ALMEIDA; FRANÇA, 2012). Essa nova postura requer um olhar mais atencioso da empresa, voltado ao seu relacionamento com a sociedade e para os impactos gerados sobre ela, em detrimento de uma visão míope, focada excessiva e exclusivamente na obtenção de lucro (SOUZA; COSTA, 2012).

A evidenciação ambiental compreende a divulgação, voluntária ou obrigatória, de informações, quantitativas ou qualitativas, aplicadas na comunicação de intenções ou efeitos ambientais decorrentes da atividade operacional da organização, direcionadas aos stakeholders (RIBEIRO, 2009). Um questionamento intimamente relacionado à evidenciação, de acordo com Rosa et al. (2012), versa sobre o tipo de informação que as organizações devem divulgar. Sabe-se que há algumas tentativas de dar padrão aos relatórios de evidenciação de informações ambientais divulgados pelas organizações. Dentre essas iniciativas, a partir de Collares et al. (2012) e Fonseca, Almeida e França (2012), destaca-se a Global Reporting Initiative (GRI) como organização não governamental internacional que promove parâmetros globais que norteiam a elaboração de relatórios de sustentabilidade.

Outra questão pertinente, envolta nessa seara de reflexão e pesquisa, diz respeito aos gastos e aos investimentos ambientais que, não necessariamente, relacionam-se com o nível de divulgação ambiental das empresas. Raupp, Correia e Fey (2009) salientam que, independente do setor em que atua a empresa, é 
imprescindivel conhecer como são evidenciados os gastos ambientais da organização, porque investimentos ambientais, considerados como ativos, representam ações preventivas e de preservação do meio ambiente. Gastos deste tipo, além de serem aplicados na correção de efeitos ambientais negativos ocasionados pela atividade da empresa, norteiam os stakeholders na compreensão do nível de comprometimento da organização junto à sociedade.

Em economias emergentes, caso do Brasil, as empresas que compõem e atuam no mercado desses países começam a compreender e identificar a demanda específica por informação de investidores que fazem uso de dados ambientais na tomada de decisão (RIBEIRO; NASCIMENTO; BELLEN, 2009). Logo, infere-se a pertinência da investigação da evidenciação ambiental também nos demais países do BRICS (Brasil, Rússia, Índia, China, e África do Sul), potenciais maiores economias do planeta, que necessitam de investidores dispostos a aplicar seus recursos no país, mas que, em contrapartida, anseiam por um grau de divulgação de informações satisfatório que extrapola a dimensão econômica, acompanhada pelas dimensões social e ambiental.

Destarte, considerando a discussão delineada, surge neste trabalho o seguinte questionamento: de que maneira estão relacionados o nível de evidenciação de informações voluntárias ambientais e o investimento ambiental nas empresas de capital aberto do BRICS? Desta questão estabelece-se como objetivo central da pesquisa determinar a relação entre 0 nível de evidenciação de informações voluntárias ambientais e 0 investimento ambiental nas empresas de capital aberto do BRICS. Adiante, o presente estudo detém como fim a realização do teste das hipóteses descritas da seguinte forma:

H1a: Há diferenças significativas no nível de evidenciação de informações voluntárias ambientais comparando-se empresas que possuem e não possuem investimento ambiental;

H1b: $O$ nível de evidenciação de informações voluntárias de caráter ambiental praticado é explicado pelo investimento ambiental das empresas de capital aberto do BRICS.

A análise que é proposta nesta pesquisa alicerça-se na consideração de que maiores níveis de divulgação de informações ambientais "acompanhem" a disclosure na realização de gastos e investimentos ambientais, proporcionais às atividades apontadas pela organização como de atenção a essa dimensão (RAUPP; CORREIA; FEY, 2009, ABREU et al., 2008). São constructos essenciais à perspectiva tomada nesta investigação as teorias da divulgação e stakeholders descritas na seção seguinte.

Mediante o estabelecimento do objetivo geral apontado, procurou-se traçar o percurso necessário ao seu alcance, caminho este apresentado pelos objetivos específicos descritos em minúcia no seguinte ordenamento: (i) Analisar o nível de evidenciação de informações ambientais de caráter voluntário quanto ao país de origem, ao impacto ambiental do setor econômico de atuação e ao tamanho das empresas; e (ii) Identificar o investimento ambiental realizado pelas empresas em termos de país de origem, impacto ambiental do setor econômico de atuação e tamanho das empresas. As variáveis "tamanho", "setor de impacto ambiental" e "país" foram adicionadas na análise tendo em vista a sua relação e influência na divulgação voluntária ambiental, verificada em diversos estudos (GOMES et al., 2012; ROVER et al., 2012).

Em termos de relevância da pesquisa, este trabalho justifica-se, a princípio, pois avalia a divulgação de informações ambientais de caráter voluntário nas maiores economias emergentes do mundo, grupo denominado BRICS, as quais, de acordo com Vieira e Veríssimo (2009, p. 514), poderão vir a se tornar a "principal força da economia global" quanto ao PIB, renda per capita e movimentação comercial e financeira. Neste ponto, faz-se necessário o desenvolvimento de estudos que abordem essa temática, nesse contexto, porque a divulgação traz como benefícios legitimidade (MACHADO; MACHADO; SANTOS, 2010), maior proximidade das empresas com potenciais investidores (fontes de financiamento) e agregação de valor à marca (FREITAS et al., 2012). Empresas deste escopo são tomadas como "exemplos" de boa conduta e, pelo respaldo econômico, têm suas práticas replicadas. Em segundo lugar, a pesquisa amplia a discussão sobre o tema da divulgação ambiental, atualmente relevante e destacada tanto academicamente quanto no cerne das corporações, considerada como estratégia que garante sobrevivência no mercado.

0 estudo encontra-se estruturado em quatro seções, além desta introdução. A seção dois compõe o arcabouço teórico e estudos empíricos anteriores que suportam e norteiam a problemática da pesquisa. $\mathrm{Na}$ seção três, são descritos os aspectos metodológicos da investigação - definição da amostra, variáveis, processo de coleta. A quarta seção explicita os resultados e as discussões desenvolvidas em torno da proposta. Na última seção, uma síntese dos principais resultados e as considerações finais como desfecho. 


\section{FUNDAMENTAÇÃO TEÓRICA}

\subsection{Perspectivas da Disclosure ambiental}

\subsubsection{Teoria da divulgação}

A primeira perspectiva de análise da disclosure ambiental, foco deste estudo, diz respeito à informação em si, prioritariamente. Em meio às transformações pelas quais passavam, e passam, as organizações em questão de forma de pensar e agir frente às problemáticas socioambientais, emerge o seguinte questionamento: o que, especificamente, evidenciar além das informações financeiras da empresa?

A teoria da divulgação forma-se como um campo positivista da contabilidade nas décadas finais do século $X X$, a qual se baseia em evidências empíricas e em modelos de análise derivados da teoria econômica para explicar e predizer a realidade (DE LUCA; MOURA; NASCIMENTO, 2012; ROVER et al., 2012). 0 principal objetivo dessa teoria é explicar o fenômeno da divulgação sob diversos aspectos. Porém, segundo Verrecchia (2001), não há uma teoria da divulgação abrangente ou integrada, não há nenhum paradigma central, nem uma única noção convincente que dê origem a todas as pesquisas subsequentes. Contudo Dye (2001) contesta tal pensamento, afirmando que essa teoria, chamada de teoria da divulgação voluntária, é uma variação da teoria dos jogos, cuja entidade divulgará informações favoráveis, ao mesmo tempo em que não evidenciará informações desfavoráveis.

A disclosure de determinada informação está sempre relacionada à sua obrigatoriedade ou não obrigatoriedade. Destarte, permanece o impasse nas mãos dos gerentes que devem avaliar se o melhor é somente divulgar o que é imposto por lei, ou divulgar informações extras aos seus stakeholders. Esse impasse, pela taxonomia proposta por Verrecchia (2001), é conhecido como divulgação baseada em julgamento. Ele se fundamenta no conceito de seleção adversa, cuja condição é a existência de assimetria informacional (SALOTTI; YAMAMOTO, 2005). Quando surge a questão sobre o quanto divulgar, Dantas, Zendersky e Niyama (2004) afirmam que deve haver um equilíbrio entre 0 custo e o benefício de divulgar a informação, com isso, determinados fatores estimulam as empresas a possuir uma maior divulgação, pois acreditam que os benefícios gerados pela divulgação superam os seus custos relacionados a essa evidenciação.

Portanto a disclosure ambiental, tema basilar da pesquisa, caracteriza-se como evidenciação de caráter voluntário, enquadrando-se como divulgação do tipo que se baseia no julgamento. A administração, que possui a discricionariedade na tomada de decisão acerca de qual informação chegará ao stakeholder para este escopo, opta por divulgar determinadas informações ambientais que podem trazem benefícios para a organização. Nesse sentido é que emerge como pertinente o debate que envolve, conjuntamente, evidenciar a informação de cunho ambiental, mas, em paralelo a isso, os investimentos e os gastos que têm relação com as atividades ambientais da organização, já que estas deveriam ser financiadas por aqueles.

\subsubsection{Teoria dos stakeholders}

A segunda perspectiva de análise da disclosure ambiental, além da teoria da divulgação, é a visão do para quem deve ser direcionada a informação. Para tanto, encaixa-se com perfeição ao problema a Teoria dos Stakeholders.

Com o surgimento da teoria dos stakeholders, quebrou-se o pensamento de Friedman (1970), para o qual a responsabilidade social de uma empresa é a geração de lucros (PINHO et al., 2007). Destarte, a única responsabilidade da administração era com aqueles que a contrataram, sendo estes os acionistas, para auferir lucros crescentes. Já a teoria dos stakeholders parte de duas perguntas: Qual é o propósito da firma? Quais responsabilidades o gerente possui sobre os demais stakeholders? (FREEMAN; WICKS; PARMAR, 2004). Desta forma, se o propósito da organização é gerar lucros, cabe à gestão atendar a esse propósito em conjunto às exigências dos diversos grupos de interesse.

Os stakeholders ou as partes interessados são um grupo de agentes econômicos, tais como os acionistas, o governo, os empregados, os clientes, os fornecedores, assim, o público em geral, o qual se relaciona direta ou indiretamente com a organização. Segundo Freeman (1984), os stakeholders são qualquer grupo ou indivíduo que pode afetar ou ser afetado pela realização dos objetivos da organização.

Freeman, Harrinson e Wicks (2007) classificam os stakeholders em dois grupos: 1) Stakeholders primários: são indivíduos ou grupo que exercem impacto direto sobre a empresa, são formados basicamente 
pelos fornecedores, clientes, empregados, investidores e proprietários; 2) Stakeholders secundários: são indivíduos ou grupos que não estão diretamente ligados às atividades econômicas da empresa, contudo podem exercer influência considerável sobre ela ou podem afetar suas operações; são formados basicamente pelo governo, ativistas, mídia, comunidade, instituições financeiras.

Com o advento da Responsabilidade Social Corporativa (RSC), a característica normativa da teoria dos stakeholders, em que cada stakeholder merece consideração por sua própria causa, e não apenas por causa de sua capacidade de promover os interesses de algum outro grupo (DONALDSON; PRESTON, 1995), ganhou um grande papel, pois diversos grupos de stakeholders pressionam as organizações a tomarem atitudes sobre questões ambientais, cabendo à administração saber gerenciar esse conflito, em que a administração deve atender a todos os grupos de interesses e ao mesmo tempo atingir as metas da organização.

\subsection{Estudos anteriores: evidenciação ambiental e investimentos ambientais}

Para Marques et al. (2010), Gomes et al. (2012) em resposta ao movimento, relativamente recente, da preocupação com as questões ambientais pela qual passam as organizações, elevaram-se os investimentos direcionados a este campo. Como consequência imediata disso, o stakeholder começa a exercer maior pressão a fim de que o reconhecimento, a mensuração e a evidenciação dos fatos que impactem o meio ambiente tornem-se mais um instrumento importante à tomada de decisão. Ressalta-se que esta relação pode ser respaldada pelas teorias da divulgação e dos stakeholders, discutidas anteriormente.

$\mathrm{Na}$ literatura encontram-se diversos estudos que avançaram ao tratar da evidenciação e do investimento ambiental. Porém se percebe maior concentração de pesquisas acerca da disclosure ambiental e uma menor frequência de estudos sobre investimentos ambientais. A realização de associação das duas temáticas, empiricamente, revela-se ainda menor, como se nota nas pesquisas descritas adiante.

Braga, Oliveira e Salotti (2009) pesquisaram a influência de determinadas variáveis (tamanho, desempenho, endividamento, riqueza criada, natureza da atividade, controle acionário e governança corporativa) sobre o nível de divulgação ambiental nas demonstrações contábeis de empresas brasileiras. As evidências analisadas sugerem que as variáveis tamanho, riqueza criada e natureza da atividade exercem influência direta e significativa sobre o nível de divulgação ambiental.

Ismail e lbrahim (2009) investigaram o grau de divulgação social e ambiental nos relatórios anuais das empresas jordanianas e examinaram se o nível de divulgação é influenciado pelo tamanho da empresa, propriedade estatal e setor. Os resultados indicam que uma associação positiva significativa é encontrada entre o tamanho da empresa e a divulgação social e ambiental, e que propriedade estatal tende a ter menor nível de divulgação socioambiental.

Gamerschlag, Möller e Verbeeten (2010) analisaram os fatores determinantes do disclosure voluntário nas 130 maiores empresas alemãs com base nos indicadores do relatório GRI. Os resultados evidenciaram que a divulgação voluntária é afetada por incentivos econômicos, como estrutura acionária, internacionalização, rentabilidade, tamanho e setor de operação da empresa.

Gomes et al. (2012) averiguaram a relação entre as características das empresas e os respectivos níveis de disclosure voluntário de informações, sob o enfoque da sustentabilidade, segundo a GRI no BRIC. Os resultados mostraram que as variáveis as variáveis desempenho, tamanho e país mostraram-se capazes de influenciar os niveis de disclosure.

Rover et al. (2012) buscaram identificar os fatores que determinam a divulgação voluntária ambiental pelas empresas brasileiras potencialmente poluidoras no período de 2005 a 2007. Foram elencados sete fatores, como tamanho, rentabilidade, endividamento, empresa de auditoria, sustentabilidade, internacionalização e publicação de relatório de sustentabilidade. Os resultados demonstraram que as variáveis tamanho da empresa, sustentabilidade, empresa de auditoria e publicação do relatório de sustentabilidade são relevantes para a explicação da evidenciação voluntária de informações ambientais.

Suttipun e Stanton (2012) verificaram as divulgações ambientais nos sites das empresas listadas na Bolsa de Valores da Tailândia (SET), e a relação entre a quantidade de divulgações e uma variedade de fatores. Os resultados indicaram que $88 \%$ das empresas da amostra forneceram informações ambientais em seus sites, e que havia uma relação entre a quantidade de divulgações e o tipo de indústria, a situação da propriedade e da empresa de auditoria.

Revista Alcance - Eletrônica - vol. 22 - n. 4 - out./dez. 2015 
Em relação aos gastos ambientais, Calixto (2007) examinou 80 companhias de capital aberto de diferentes setores listadas na BM\&FBovespa entre os anos de 1997 a 2005, objetivando analisar a sua evidenciação ambiental. A pesquisa explicitou que informações acerca de multas e processos ambientais, gastos com proteção, licenciamento, certificação e passivos ambientais tiveram maior variação no período. A informação sobre investimentos ambientais foi crescente até 2003 (31\%), mas se manteve estável, com decréscimo em anos posteriores.

Vellani e Nakao (2009) analisaram se a redução de custos é um fator relevante na decisão de investimentos ambientais. Comprovou-se neste estudo, como principal resultado, que 0 investimento em desenvolvimento sustentável reduz custos para as empresas. Segundo os autores, salvaguardar a concepção de que esse tipo de investimento não agrega benefício econômico e financeiro é falsa em múltiplas situações.

Machado et al. (2006) confirmaram seu pressuposto de que empresas dos setores de alto impacto, tais como petróleo e gás, mineral, energia elétrica, entre outros, realizam mais investimento ambiental que setores que ofertam seus bens, predominantemente, ao mercado interno. Barcellos, Oliveira e Carvalho (2009) também encontraram essa relação ao estudarem a indústria brasileira nos anos de 1997 e 2002. Observaram um crescimento de $98 \%$ no valor investido. Machado et al. (2012) descobriram relação entre o nível de investimentos ambientais e a inclusão de empresas no Índice de Sustentabilidade Empresarial (ISE) da BM\&FBovespa. Bufoni (2009), ao analisar a relação entre desempenho e investimento ambiental, utilizou como variável de controle o tamanho da empresa. O resultado encontrado é que esta variável explicava o investimento ambiental com nível de significância de $1 \%$.

Marques et al. (2010) estudaram a relação entre investimento e evidenciação ambiental no período de 2006 a 2008, tomando como base de dados o modelo de balanço social do IBASE (investimento) e o relatório do GRI (evidenciação). Os resultados apontaram crescimento do investimento total das empresas e, adicionalmente, houve acompanhamento da evidenciação de ações ambientais com o nivel de investimentos.

Raupp, Correia e Fey (2009) investigaram os investimentos ambientais de 13 empresas do setor elétrico no período de 2005 a 2006. Os resultados evidenciaram que, em termos quantitativos, os investimentos foram significativos para o setor, pois na transição do período estudado teve ascensão de $R \$ 28$ milhões $(R \$ 16$ $\mathrm{mi}-2005 ; \mathrm{R} \$ 44 \mathrm{mi}-2006$ ), resultado $175 \%$ maior ao do ano comparado.

Após a apresentação dos estudos empíricos anteriores, conclui-se que a presente pesquisa tem como diferencial ante as demais, portanto, a abordagem de análise da evidenciação ambiental como impactada pela realização de investimentos ambientais (inclusive por organizações inseridas em um contexto econômico emergente internacional). $O$ cenário do qual se fala é o BRICS, no qual Brasil, Rússia, Índia, China e África do Sul constituem o grupo de maiores economias emergentes.

\section{MÉTODO DE PESQUISA}

\subsection{Tipologia}

Tendo em vista o seu objetivo principal, esta pesquisa, no tocante aos fins, define-se como descritiva. Collis e Hussey (2005) ratificam o exposto ao afirmarem que este tipo de estudo visa descrever 0 comportamento dos fenômenos, especificamente para este caso, a disclosure ambiental nas maiores economias emergentes.

Quanto aos meios, a proposta estabelece-se como documental, pois detém como fonte de dados os Relatórios de Sustentabilidade (RS) no modelo 3.0 da Global Reporting Initiative (GRI), disponibilizados pelas empresas analisadas. Todos os documentos foram buscados no endereço eletrônico da GRI (www.database.globalreproting.org), divulgados no período de 2012, alusivos ao ano-base de 2011 - período mais recente com maior nível de reporting do RS. Quando não encontrados, procedeu-se com a busca do relatório no website das empresas. Martins e Theóphilo (2009) caracterizam a pesquisa documental como semelhante à bibliográfica, porém distinguindo desta pelo fato de as fontes de dados, apesar de serem secundárias, não passarem por edição.

Quanto à abordagem, a investigação é tomada como quantitativa, pois após o levantamento das variáveis: (1) evidenciação ambiental; e (2) investimento ambiental, procedeu-se com a aplicação de duas análises: (i) teste de diferença de médias; e (ii) análise de regressão linear múltipla. Como consta em Sampieri, Collado e Lucio (2013), a pesquisa quantitativa usa a coleta de dados para testar hipóteses com base na medição numérica e na análise estática para estabelecer padrões de comportamento. Recorda-se que as 
hipóteses da pesquisa propõem: existir diferença no nível de divulgação ambiental, quando comparadas empresas que possuem e não possuem investimento ambiental; e ser a evidenciação ambiental explicada pelo investimento ambiental realizado pelas empresas. Todas as análises desenvolveram-se por intermédio do Statistical Package for the Social Sciences 21.0 (SPSS).

\subsection{População e amostra do estudo}

A amostra do estudo é não probabilística. De início, procedeu-se com a seleção das empresas do BRICS constantes na base de dados do GRI, ou seja, empresas que cumprem as diretrizes de divulgação propostas pela instituição. No total foram identificadas 405 empresas, segmentadas em três categorias: a) listadas; b) não listadas; e c) não aplicada (informação desconhecida pela base de dados). Deste ponto, deve-se reiterar que o propósito da pesquisa gira em torno da necessidade que possuem os diversos stakeholders, usuários da informação reportada pelas organizações e, por isso, tomadores de decisão, da avaliação de demanda informacional específica - as informações ambientais. Discutiu-se que as questões de cunho ambiental passaram a ser amplamente debatidas pela sociedade e o reflexo dessa mudança de paradigma foi a adoção de práticas ambientalmente responsáveis pelas organizações. 0 investidor considera, na escolha de onde aplicar seu investimento, negócios mais rentáveis, porém conscientes das questões ambientais.

Assim sendo, o primeiro critério para pertencimento ao conjunto analisado é a listagem em bolsa de valores. Empresas não listadas detêm menos visibilidade no mercado, por não terem seu capital aberto. Com isso, permaneceram no estudo, após a aplicação desta consideração, 202 empresas, todas de capital aberto, pertencentes ao BRICS. Da maneira que fora descrito na subseção anterior, foram analisados os RS-GRI 3.0 (mais recentes divulgados) das empresas pertencentes aos paises do BRICS, tendo em vista os objetivos propostos. Seguiu-se com a identificação de todas as empresas que satisfaziam a este segundo critério, contatando-se a ocorrência de 143 empresas.

Por fim, tendo em vista a fidedignidade da informação reportada pelas empresas pesquisadas, permaneceram no estudo apenas aquelas que tinham seu relatório de sustentabilidade com algum nível de aplicação $(C, C+, B, B+, A$ ou $A+)$. $O$ nível de aplicação indica o quão aderente é a empresa às diretrizes sugeridas pelo GRI. Empresas que não alcancem sequer o nível $C$, patamar mais baixo, não aderem satisfatoriamente à divulgação dos indicadores econômicos, ambientais e sociais. Reforça-se que 0 estudo trabalhou apenas a dimensão ambiental. Consolidaram a amostra preliminar da pesquisa, portanto, depois dos critérios enumerados, 102 empresas. É válido especificar que as informações de listagem, o pertencimento ao BRICS e o nível de aplicação são destinadas pela GRI.

No entanto, durante a fase de coleta dos dados, algumas empresas não tinham evidenciado na base de dados da GRI o relatório de sustentabilidade relativo ao período em questão, mesmo sendo a informação da base de coleta positiva em relação ao reporting. Essas empresas foram excluídas, perfazendo uma amostra definitiva de 82 empresas. A presente pesquisa ressalta e reconhece a limitação do número restrito de empresas em relação aos países do BRICS. Por exemplo, o Brasil é possuidor de 25 elementos da amostra, enquanto que a China responde apenas por 6 deles. Tal fato deve ser levado em consideração, feitas análises comparativas e discussões com outras pesquisas. No trabalho de Lu e Abeysekera (2014), que compreendeu apenas firmas da China, viu-se que diversos fatores, como o setor, o porte e o desempenho, podem interferir na divulgação de caráter ambiental. Os autores comentam que as partes interessadas (stakeholders) podem fortalecer a demanda por esse tipo de divulgação que, na China, tende a ser fraca, com algumas exceções. Isso poderia explicar 0 número reduzido de firmas daquele país. Nesse sentido, Alon et al. (2010) reforçam que as empresas não "percebem" o potencial informativo das questões atreladas à responsabilidade social corporativa.

\subsection{Coleta dos dados}

Iniciada a coleta dos dados que possibilitou a determinação do nível de divulgação das informações ambientais das empresas e os gastos ambientais por elas despendidos, quando houvesse, elaborou-se um checklist de divulgação dos indicadores ambientais (EN) da GRI.

Seguiu-se com uma faixa de pontuação ( 0 a 2 ) que dependia do disclosure efetivado pela empresa. Logo, empresas que informaram em completude 0 indicador ambiental recebiam pontuação máxima. Para aquelas que realizaram evidenciação parcial do indicador, atribuía-lhes pontuação mediana (1). Finalmente, àquelas que não tinham a prática de divulgar o indicador, pontuava-se zero. Segundo a versão do RS-GRI 3.0,

Revista Alcance - Eletrônica - vol. 22 - n. 4 - out./dez. 2015 
são no total 30 indicadores, segmentados em essenciais (17) e adicionais (13). Relativizou-se a divulgação observada pela divulgação máxima, sendo mensurado o nível de divulgação ambiental da empresa. Para o investimento ambiental, interessava principalmente ao estudo a divulgação do indicador "EN30" que evidencia o total de investimentos e gastos em proteção ambiental, por tipo. Quando divulgado, foi procedida à conversão do valor em moeda de cada país para o padrão monetário do Brasil $(R \$)$, para fins de comparação. As taxas de câmbio foram obtidas junto ao Banco Central do Brasil (BACEN). Assim, para as contas de resultado foi utilizada a taxa cambial média de 2011, conforme orientação da IAS 21 (IFRS, 2003).

A seguir, dispõem-se todas as medidas utilizadas nas análises preconizadas nesta pesquisa, conforme apresenta 0 Quadro 1.

Quadro 1 - Variáveis utilizadas na pesquisa

\begin{tabular}{|c|c|c|c|}
\hline \multicolumn{2}{|c|}{ Variável } & Descrição & Proxy \\
\hline $\begin{array}{c}\text { Disclosure } \\
\text { ambiental total }\end{array}$ & DISC_T & $\begin{array}{c}\text { Evidenciação dos indicadores } \\
\text { ambientais do GRI }\end{array}$ & $\begin{array}{c}\text { Total de Indicadores evidenciados/ } \\
\text { Total de indicadores }\end{array}$ \\
\hline $\begin{array}{c}\text { Disclosure } \\
\text { ambiental } \\
\text { essencial }\end{array}$ & DISC_E & $\begin{array}{c}\text { Evidenciação dos indicadores } \\
\text { ambientais essenciais do GRI }\end{array}$ & $\begin{array}{c}\text { Total de Indicadores essenciais evidenciados/ } \\
\text { Total de indicadores essenciais }\end{array}$ \\
\hline $\begin{array}{c}\text { Investimento } \\
\text { ambiental }\end{array}$ & INVEST & $\begin{array}{c}\text { Gastos com o meio ambiente } \\
\text { (Indicador EN30 - GRI) }\end{array}$ & $\begin{array}{c}\text { Valor divulgado de investimentos } \\
\text { (em R\$) }\end{array}$ \\
\hline País & IDH & $\begin{array}{c}\text { Índice de Desenvolvimento Humano } \\
\text { do País }\end{array}$ & $\begin{array}{c}\text { Brasil (0,718); Rússia (0,755); Índia (0,547); China } \\
\text { (0,687); África do Sul }(0,619)\end{array}$ \\
\hline Impacto & IMP & $\begin{array}{c}\text { Impacto ambiental do setor segundo } \\
\text { o FTSE4Good Index }\end{array}$ & $\begin{array}{c}\text { Alto impacto - 3; Médio impacto - 2; } \\
\text { Baixo impacto - 1 }\end{array}$ \\
\hline Tamanho & TAM & $\begin{array}{c}\text { Faturamento bruto na empresa no } \\
\text { período }\end{array}$ & $\begin{array}{c}\text { Ln do faturamento bruto } \\
\text { (em R\$) }\end{array}$ \\
\hline
\end{tabular}

Fonte: Dados da pesquisa.

Como fora observado, para aplicação do modelo quantitativo, aplicou-se o logaritmo natural ao valor do faturamento bruto das empresas (tamanho) devido à discrepância inerente à medida. Em relação ao impacto ambiental dos setores das empresas, menciona-se o FTSE Group, instituição responsável por elaborar índices relativos a empresas com cotação em bolsa. Dentre os quais, desenvolveu-se por ela o "FTSE4Good Index", que estabelece a mensuração do desempenho de empresas que procuram atender a padrões de responsabilidade social com reconhecimento global. Por ele, são elencados os setores econômicos das empresas, de alto, médio e baixo impacto ambiental. Como nesta pesquisa trabalha-se com as empresas do BRICS, esta classificação apresenta-se relevante. Dessa forma, atentados esses critérios e aplicados os procedimentos mencionados, partiu-se para o tratamento dos dados.

\subsection{Tratamento estatístico dos dados}

O tratamento estatístico dos dados de maneira a serem testadas as hipóteses do estudo ante o objetivo proposto compreendeu duas análises principalmente: (i) teste de diferença de médias e (ii) análise de regressão linear múltipla.

A aplicação do teste de diferença de médias, neste caso, investigando se o nível médio de divulgação ambiental apresentava-se distinto nas empresas possuidoras de investimento ambiental, comparadas àquelas que não possuíam este investimento, demandava exame acerca da normalidade da variável disclosure ambiental. Realizado o teste de Kolmogorov-Smirnov, verificou-se a não normalidade da variável disclosure (total e essencial). Dessa forma, optou-se pelo teste de Mann-Whitney, um dos testes não paramétricos mais poderosos na comparação de médias em amostras que violaram a hipótese da normalidade (FÁVERO et al., 2009). 
Em seguida, na análise de regressão linear múltipla que, segundo Hair Jr. et al. (2009, p. 154), busca "usar as variáveis independentes cujos valores são conhecidos para prever os valores da variável dependente selecionada", tratou-se a divulgação ambiental (total e essencial) como variável explicada pelo investimento ambiental das empresas e, complementarmente, pelo IDH dos países do BRICS, pelo impacto ambiental dos setores das empresas e pelo seu tamanho. Assim, foram edificadas as Equações 1a e 1b, descritas adiante:

Modelo 1: Divulgação total $\left.\right|_{(i)}=\beta_{0}+\beta_{1}$ Investimento ambiental $_{(i)}+\beta_{2} I_{D H_{(i)}}+\beta_{3}$ Impacto ambiental $_{(i)}+\beta_{4} \operatorname{Tamanho}_{(\mathrm{i})}$ $+\varepsilon_{(i)}$

Equação 1a

Modelo 2: Divulgação essencial $\left.\right|_{(i)}=\beta_{0}+\beta_{1}{\text { Investimento } \text { ambiental }_{(i)}+\beta_{2} \mid \mathrm{DH}_{(\mathrm{i})}+\beta_{3} \operatorname{lmpacto~}_{\text {ambiental }}(\mathrm{i})}+$ $\beta_{4} \operatorname{Tamanho}_{(i)}+\varepsilon_{(i)}$

Equação 1b

Nos modelos, $\beta_{0}$ refere-se ao intercepto da reta ajustada da equação e $\varepsilon_{(i)}$ representa o termo de erro. Como observado, no modelo 1 procura-se examinar a influência das variáveis independentes na divulgação total, ou seja, na disclosure considerada primária (comuns a todas as empresas) e naquela tomada como adicional pela GRI. Já no modelo 2, a influência é verificada apenas na divulgação essencial.

\section{ANÁLISE E DISCUSSÃO DOS RESULTADOS}

\subsection{Perfil da amostra}

A Tabela 1 apresenta as empresas dos países que compõem o BRICS quanto ao impacto ambiental do setor econômico que são alto, médio e baixo.

Tabela 1 - Caracterização da amostra quanto ao impacto ambiental

\begin{tabular}{c|c|c|c|c|c|c|c|c}
\hline Característica & Categoria & Brasil & Rússia & Índia & China & África do Sul & Total & $\%$ \\
\hline \multirow{3}{*}{$\begin{array}{c}\text { Impacto Ambiental do } \\
\text { Setor Econômico }\end{array}$} & Alto & 14 & 13 & 8 & 2 & 10 & 47 & 57 \\
\cline { 2 - 10 } & Médio & 8 & 4 & 3 & 2 & 7 & 24 & 29 \\
\cline { 2 - 9 } & Baixo & 3 & 2 & 2 & 2 & 2 & 11 & 13 \\
\hline \multicolumn{2}{c}{ Total } & 25 & 19 & 13 & 6 & 19 & 82 & 100 \\
\hline
\end{tabular}

Fonte: Dados da pesquisa.

Assim, observa-se, de acordo com a Tabela 1, que mais da metade das empresas em estudo são caracterizadas como setor econômico de alto impacto (57\%), sendo que o restante das empresas (43\%) compõe as empresas de setor econômico de médio (29\%) e baixo (13\%) impacto. Dentre os países, o Brasil apresentou mais empresas no setor de alto impacto, seguido pela Rússia e África do Sul. Em termos relativos, considerando a quantidade total de empresas por país, o ordenamento observado é Rússia, Índia, Brasil, África do Sul e China. Deve-se considerar, no entanto, o número de empresas por país, ora elevado, ora reduzido, dependendo da economia considerada.

Prosseguiu-se com a alocação das empresas de cada país por faixa de tamanho calculada por meio dos quartis do faturamento ( $1^{\circ}$ quartil: $R \$ 0,00$ a $R \$ 1.349 .234,61 ; 2^{\circ}$ quartil: $R \$ 1.349 .234,62$ a $R \$$ 5.738.347,40; $3^{0}$ quartil: $\mathrm{R} \$ 5.738 .347,41$ a $\mathrm{R} \$ 16.956 .195,00 ; 4^{\circ}$ quartil: $\mathrm{R} \$ 16.956 .195,01$ a $\left.\mathrm{R} \$ 270.783 .455,16\right)$, como expõe a Tabela 2. 
Tabela 2 - Caracterização da amostra quanto ao tamanho

\begin{tabular}{|c|c|c|c|c|c|c|c|c|c|c|c|}
\hline Tamanho & \multicolumn{2}{|c|}{ Brasil } & \multicolumn{2}{|c|}{ Rússia } & \multicolumn{2}{|c|}{ Índia } & \multicolumn{2}{|c|}{ China } & \multicolumn{2}{|c|}{ África do Sul } & Total \\
\hline $1^{\circ}$ quartil & 4 & $16 \%$ & 4 & $21 \%$ & 3 & $23 \%$ & 2 & $33 \%$ & 8 & $42 \%$ & 21 \\
\hline $2^{\circ}$ quartil & 11 & $44 \%$ & 0 & $0 \%$ & 3 & $23 \%$ & 0 & $0 \%$ & 6 & $32 \%$ & 20 \\
\hline $3^{\circ}$ quartil & 6 & $24 \%$ & 3 & $16 \%$ & 5 & $38 \%$ & 1 & $17 \%$ & 5 & $26 \%$ & 20 \\
\hline $4^{0}$ quartil & 4 & $16 \%$ & 12 & $63 \%$ & 2 & $15 \%$ & 3 & $50 \%$ & 0 & $0 \%$ & 21 \\
\hline Total & 25 & $100 \%$ & 19 & $100 \%$ & 13 & $100 \%$ & 6 & $100 \%$ & 19 & $100 \%$ & 82 \\
\hline
\end{tabular}

Fonte: Dados da pesquisa.

Observa-se, a partir da Tabela 2, que a Índia acompanha Rússia e China ao possuir mais da metade de suas empresas enquadradas entre $03^{\circ}$ e $4^{\circ}$ quartil (maiores níveis de faturamento). Em sentido oposto, Brasil e África do Sul contêm, nesta sequência, $60 \%$ e $74 \%$ de suas empresas nos quartis inferiores, explicando os resultados demonstrados pela estatística descritiva realizada na Tabela 3. Deve-se reconhecer o número restrito de empresas de países como a China, que possui apenas seis empresas.

\subsection{Nível de evidenciação ambiental no BRICS}

Em atenção ao primeiro objetivo específico da pesquisa, a Tabela 3 apresenta o nível de divulgação ambiental das empresas dos países que compõem o BRICS quanto à disclosure total e essencial.

Tabela 3 - Indicadores de disclosure ambiental (total e essencial) no BRICS

\begin{tabular}{|c|c|c|c|c|c|c|c|c|c|c|c|c|}
\hline País & \multicolumn{2}{|c|}{ Brasil } & \multicolumn{2}{|c|}{ Rússia } & \multicolumn{2}{|c|}{ Índia } & \multicolumn{2}{|c|}{ China } & \multicolumn{2}{|c|}{$\begin{array}{l}\text { África do } \\
\text { Sul }\end{array}$} & \multicolumn{2}{|c|}{ BRICS } \\
\hline Medida & $\mathrm{T}(\%)$ & $E(\%)$ & $\mathrm{T}(\%)$ & $E(\%)$ & $\mathrm{T}(\%)$ & $E(\%)$ & $\mathrm{T}(\%)$ & $E(\%)$ & $\mathrm{T}(\%)$ & $E(\%)$ & $\mathrm{T}(\%)$ & $E(\%)$ \\
\hline Média & 64 & 66 & 46 & 52 & 77 & 89 & 56 & 68 & 55 & 64 & 59 & 66 \\
\hline Máximo & 100 & 100 & 100 & 100 & 100 & 100 & 100 & 100 & 97 & 100 & 100 & 100 \\
\hline Mínimo & 0 & 0 & 0 & 0 & 50 & 53 & 7 & 9 & 5 & 9 & 0 & 0 \\
\hline Desvio Padrão & 33 & 33 & 32 & 33 & 17 & 14 & 36 & 43 & 27 & 27 & 30 & 32 \\
\hline
\end{tabular}

Fonte: Dados da pesquisa.

A partir da Tabela 3, observa-se que a evidenciação total (T) no BRICS foi de $59 \%$ e a essencial (E) foi de $66 \%$, demonstrando que as empresas preocupam-se primeiramente em informar as questões ambientais essenciais e, posteriormente, as adicionais. Esses números se referem à análise das 82 empresas em conjunto, ou seja, resultados do grupo. $O$ país que apresentou os melhores níveis de evidenciação ambiental (T e E) foi a Índia (T - 77\%; E - 89\%), seguida do Brasil (T - 64\%; E - 66\%), da China (T - 56\%; E - 68\%), da África do Sul (T - 55\%; E - 64\%), e da Rússia (46\%, 52\%). Atenta-se ainda que, tanto no Brasil quanto na Rússia, houve empresas que não evidenciaram informações ambientais. Além disso, todas as empresas dos países do BRICS evidenciaram a totalidade das questões ambientais essenciais propostas pela GRI, e que a África do Sul foi 0 único país que não evidenciou completamente as questões ambientais totais (97\%).

A Figura 1 demonstra o nível de disclosure ambiental total e essencial por setores de impacto ambiental das empresas dos países que compõem o BRICS. Destarte, as empresas são caracterizadas em alto, médio e baixo impacto ambiental. 
Figura 1 - Nível de disclosure ambiental por setor de impacto ambiental

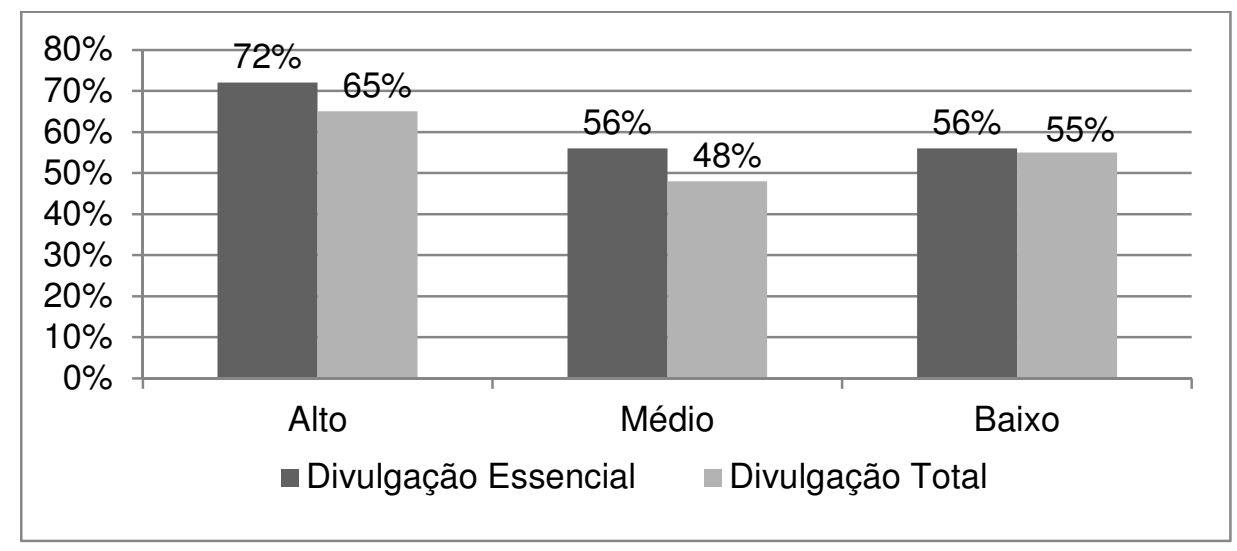

Fonte: Dados da pesquisa.

Observa-se na Figura 1 que o setor de alto impacto apresenta o maior nível de evidenciação total (65\%) e essencial (72\%), corroborando com os estudos de Braga, Oliveira e Salotti (2009), e Suttipun e Stanton (2012), para os quais o setor influencia na evidenciação ambiental. Mais além, observa-se que os setores de médio e baixo impacto apresentam o mesmo nível de evidenciação ambiental essencial (56\%) e que o setor de médio impacto ambiental apresenta o menor nível de evidenciação ambiental total (48\%).

A Figura 2 mostra o nível de disclosure ambiental total e essencial quanto ao tamanho das empresas dos países que compõem o BRICS.

Figura 2 - Nível de disclosure ambiental por tamanho

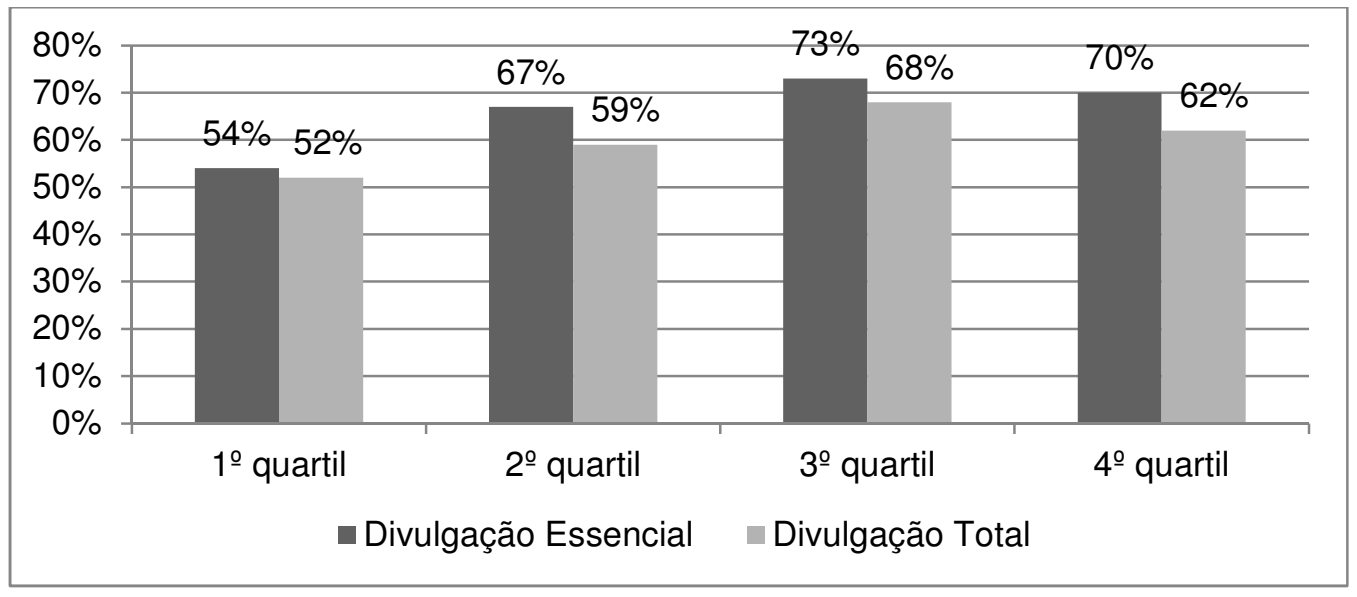

Fonte: Dados da pesquisa.

Constata-se na Figura 2 que as empresas que compõem $03^{\circ}$ quartil apresentam o maior nível de evidenciação ambiental total (68\%) e essencial (73\%), seguido das empresas que compõem $04^{0}$ quartil com nivel de divulgação ambiental total de $62 \%$ e essencial de $70 \%$, esse resultado corrobora com os estudos de Braga, Oliveira e Salotti (2009), Gomes et al. (2012), Rover et al. (2012) para os quais o tamanho da organização influencia no nível de divulgação ambiental. Adicionalmente, as empresas com o menor nível de evidenciação ambiental total e essencial foram as presentes no $1^{\circ}$ quartil, reforçando o pressuposto de que empresas menores apresentam menor nível de evidenciação ambiental.

\subsection{Investimento ambiental no BRICS}

Refere-se esta seção ao segundo objetivo específico da pesquisa, que será delineado adiante, conforme resultados evidenciados e discutidos nas Tabelas 4, 5 e 6 . 
A primeira delas, Tabela 4, demonstra o nível de evidenciação dos investimentos ambientais, bem como a estatística descritiva dos valores investidos por país do BRICS.

Tabela 4 - Nível de investimento ambiental por país no BRICS

\begin{tabular}{l|c|r|r|r|r|r|r}
\hline \multicolumn{1}{c|}{ Países } & \multicolumn{1}{c|}{ Empresas } & \multicolumn{2}{c|}{ Relatos } & \multicolumn{1}{c|}{ Média } & \multicolumn{1}{c|}{ Desvio Padrão } & \multicolumn{1}{c}{ Máximo } & \multicolumn{1}{c}{ Mínimo } \\
\hline Brasil & 25 & 15 & $60 \%$ & $141.428,31$ & $439.849,71$ & $1.724 .073,91$ & 60,00 \\
\hline Rússia & 19 & 11 & $58 \%$ & $5.342 .815,07$ & $8.556 .441,27$ & $23.348 .647,58$ & $3.889,72$ \\
\hline Índia & 13 & 9 & $69 \%$ & $5.745,88$ & $7.681,61$ & $17.105,09$ & 125,15 \\
\hline China & 6 & 1 & $17 \%$ & $104.712,76$ & $104.712,76$ & $104.712,76$ & $104.712,76$ \\
\hline África do Sul & 19 & 6 & $32 \%$ & $7.440,93$ & $16.125,06$ & $40.249,59$ & 53,08 \\
\hline Total & 82 & 42 & $51 \%$ & $1.454 .606,23$ & $4.839 .583,46$ & $23.348 .647,58$ & 53,08 \\
\hline
\end{tabular}

Fonte: Dados da pesquisa.

Segundo a Tabela 4, percebe-se que nem todas as empresas divulgaram investimentos ambientais, ou por não realizarem, ou por não serem esses gastos materiais à divulgação. Dessa forma, o nível de evidenciação de investimentos ambientais observado é de $51 \%$ (42 empresas) do total da amostra. Elas investiram, em média, aproximadamente $2,5 \%$ de seu faturamento bruto com questões ambientais. Tiveram 0 maior e o menor nível de divulgação, respectivamente, Índia (69\%) e China (17\%). A priori, não se pôde estabelecer qualquer relação entre evidenciação e média investida por país, mas um contraste foi apresentado quando China, Brasil e Rússia (maiores médias de investimento), as três maiores economias do BRICS, foram superadas em evidenciação pela Índia. Os dados apresentam elevada dispersão e amplitude, provavelmente devido às distinções de tamanho e setor de impacto ambiental que serão testadas na correlação. É sempre importante recordar que a quantidade de empresas é discrepante entre os países, restringindo, até certo ponto, essas inferências.

Calixto (2007) encontrou percentuais de evidenciação de investimentos ambientais em 80 empresas de capital aberto, analisando o período de 1997-2005, as quais chegaram a no máximo $25 \%$. Apenas a China obteve índice inferior a este, lembrando-se de que sua amostra é de apenas 6 empresas. Esse resultado corrobora as conclusões de Vellani e Nakao (2009), que analisaram a relação custo x benefício na decisão de se investir em meio ambiente. Segundo os autores, as empresas estão se adaptando a esse novo contexto visando à continuidade, à produtividade, à eficiência e à qualidade ambiental. Em referência à parcela do faturamento consumida com investimentos ambientais, Marques et al. (2010) encontraram percentuais pequenos (no máximo 0,43\%) no período de 2006-2008. Raupp, Correia e Fey (2009), entre 2005-2006, obtiveram resultados pouco maiores que 1,75\%, o que evidencia também uma crescente nos investimentos desta espécie.

A Tabela 5 verifica o nível de evidenciação de investimentos ambientais em relação aos setores de alto, médio e baixo impacto ambiental.

Tabela 5 - Nível de investimento ambiental por setor de impacto

\begin{tabular}{c|c|c|c|r}
\hline Impacto & Total de Empresas & Evidenciação & Evidenciação (\%) & Média de Investimento \\
\hline Alto & 47 & 28 & 60 & $\mathrm{R} \$ 673.848,82$ \\
\hline Médio & 24 & 10 & 42 & $\mathrm{R} \$ 14.806,39$ \\
\hline Baixo & 11 & 4 & 36 & $\mathrm{R} \$ 10.781,50$ \\
\hline Total & $\mathbf{8 2}$ & $\mathbf{4 2}$ & $\mathbf{5 1}$ & $\mathrm{R} \$ 2.473 .196,52$ \\
\hline
\end{tabular}

Fonte: Dados da pesquisa.

Da forma como era esperado, infere-se, a partir da Tabela 5, que tanto o nível de evidenciação de investimentos ambientais como a média de investimentos ambientais realizados são maiores nas empresas 
pertencentes a setores de alto impacto ambiental e menores nas empresas incluídas em setores de impacto inferior. Os achados corroboram os resultados de Machado et al. (2006) e Barcellos, Oliveira e Carvalho (2009), que encontraram essa mesma relação. Essa conclusão respalda-se à medida que os setores de alto impacto são mais poluidores e, por isso, podem sofrer maiores pressões dos stakeholders. Concordam Raupp, Correia e Fey (2009) e Machado et al. (2012), ao defenderem que o investimento ambiental é indício de comprometimento da empresa com a responsabilidade social, a sustentabilidade e a sociedade.

Descreve-se, ainda, a relação entre o nível de investimento ambiental, evidenciado e gasto, quanto ao tamanho das empresas que compõem a amostra, como sugere a Tabela 6.

Tabela 6 - Nível de investimento ambiental por tamanho

\begin{tabular}{l|c|c|c|r}
\hline Tamanho & Empresas & Disclosure & Disclosure (\%) & \multicolumn{1}{|c}{ Investimento Médio } \\
\hline $1^{\circ}$ quartil & 21 & 9 & $43 \%$ & $4.759 .833,00$ \\
\hline $2^{\circ}$ quartil & 20 & 12 & $60 \%$ & $11.178,84$ \\
\hline $3^{\circ}$ quartil & 20 & 10 & $50 \%$ & $55.057,56$ \\
\hline $4^{\circ}$ quartil & 21 & 11 & $52 \%$ & $5.486 .457,75$ \\
\hline
\end{tabular}

Fonte: Dados da pesquisa.

Para a Tabela 6, o nível de investimento ambiental das empresas neste item não evidenciou relação com o tamanho das empresas. A disclosure foi maior nas empresas do $2^{\circ}$ quartil e menor naquelas inclusas no $1^{\circ}$ quartil. Porém essa divergência foi amenizada quando confrontados o investimento ambiental médio e 0 tamanho das empresas, porque as empresas do $4^{\circ}$ quartil detiveram a maior média de investimentos. No entanto, o grupo de menores empresas teve investimento médio de $\mathrm{R} \$ 4.759 .833,00$, segundo maior nível.

\subsection{Teste de diferença de médias}

Referente à primeira hipótese de teste $(\mathrm{H} 1 \mathrm{a})$, levantada neste estudo, foi realizado o teste de diferença de médias de Mann-Whitney, propondo-se verificar se a divulgação (ambiental) média nos países do BRICS fazia-se distinta nas empresas que evidenciaram investimento ambiental, denominado grupo 1, e naquelas que não possuíam valores no indicador EN30, grupo 2. Os resultados encontram-se dispostos na Tabela 7.

Tabela 7 - Estatística de teste Mann-Whitney: divulgação ambiental nas empresas com investimento ambiental (Grupo 1) e sem investimento ambiental (Grupo 2)

\begin{tabular}{l|c|c|c|c|c|c|c|c}
\hline \multicolumn{2}{c|}{ Disclosure ambiental } & N & $\begin{array}{c}\text { Média do } \\
\text { Rank }\end{array}$ & $\begin{array}{c}\text { Soma dos } \\
\text { Ranks }\end{array}$ & $\begin{array}{c}\text { Mann- } \\
\text { Whitney }\end{array}$ & Wilcoxon W & Z & Sig. \\
\hline \multirow{2}{*}{ Total } & Grupo 1 & 42 & 54,40 & 2285,00 & 298,00 & 1118,00 & $-5,035$ & $0,000^{* * *}$ \\
\cline { 2 - 9 } & Grupo 2 & 40 & 27,95 & 1118,00 & & & & \\
\hline \multirow{2}{*}{ Essencial } & Grupo 1 & 42 & 50,08 & 2103,50 & 479,50 & 1299,50 & $-3,374$ & $0,001^{* * *}$ \\
\cline { 2 - 9 } & Grupo 2 & 40 & 32,49 & 1299,50 & & & \\
\hline
\end{tabular}

Nota: ${ }^{* *}$ Significante a 0,01.

Fonte: Dados da pesquisa.

Depreende-se, a partir da Tabela 7, que para um nível de significância de 1\%, há diferenças significativas na disclosure ambiental nos grupos 1 e 2, evidência suficiente para não rejeitar a hipótese H1a. No entanto, pode-se concluir ainda que, tanto na divulgação ambiental "total" quanto na divulgação ambiental "essencial", o rank médio do grupo 1 (empresas com investimento ambiental) é superior àquele observado no grupo 2. Esse resultado sinaliza uma possível relação entre o nível de divulgação relacionada ao escopo ambiental e o investimento que é realizado pelas empresas do BRICS. Ou seja, empresas que têm algum tipo de

Revista Alcance - Eletrônica - vol. 22 - n. 4 - out./dez. 2015 
investimento ambiental divulgam, em média, mais informações ambientais que aquelas que não realizam investimentos neste sentido. Conforme indicam Raupp, Correia e Fey (2009), os gastos ou investimentos ambientais ajudam a nortear o stakeholder a compreender quão comprometida está a empresa ambientalmente.

Mesmo diante das evidências demonstradas nas análises descritivas constantes nas subseções 4.1, 4.2 e 4.3, além da discussão introduzida pelos resultados do teste de diferença de médias, ainda restava a avaliação do efeito influência das medidas abordadas nesta pesquisa, especialmente 0 investimento ambiental, na divulgação, também ambiental, das empresas do BRICS. Esta verificação é apresentada na subseção seguinte.

\subsection{Análise de correlação e regressão linear múltipla}

Anterior à análise de regressão, esta seção destina-se à análise da correlação entre as variáveis "divulgação ambiental" e "investimento ambiental" nas empresas de capital aberto do BRICS. A avaliação foi ampliada sendo verificado o nível de correlação entre as variáveis em termos de "país", "impacto ambiental do setor econômico" e "tamanho" da empresa, a fim de serem confirmadas ou não as evidências observadas nas seções antecedentes. 0 teste de Kolmogorov-Smirnov apontou que as observações não atendiam ao pressuposto da normalidade: Invest. (sig. $=0,000)$, Disc_T (sig. $=0,008)$, Disc_E $($ sig. $=0,000)$, IDH (sig. = $0,000)$ e Tam. (sig. $=0,000$ ). Assim, fora aplicado o teste de correlação de Spearman, não paramétrico, explicitado na Tabela 8.

Tabela 8 - Matriz de correlação (teste de Spearman)

\begin{tabular}{c|c|c|c|c|c|c}
\hline VARIÁVEIS & INVEST & DISC_T & DISC_E & IDH & IMP & TAM \\
\hline INVEST & 1,000 & & & & & \\
\hline DISC_T & $0,531^{* * *}$ & 1,000 & & & & \\
\hline DISC_E & $0,329^{* * *}$ & $0,891^{* * *}$ & 1,000 & & & \\
\hline IDH & $0,225^{* *}$ & $-0,206^{*}$ & $-0,286^{* *}$ & 1,000 & & \\
\hline IMP & $0,287^{* * *}$ & $0,216^{*}$ & $0,192^{*}$ & 0,075 & 1,000 & \\
\hline TAM & 0,123 & 0,158 & 0,175 & $0,232^{* *}$ & $-0,026$ & 1,000 \\
\hline
\end{tabular}

$\left({ }^{* * *}\right)$ Correlação significante a um nível de 0,$01 ;\left(^{* *}\right)$ Correlação significante a um nível de 0,$05 ;\left({ }^{*}\right)$ Correlação significante a um nível de 0,10 .

Fonte: Dados da pesquisa.

Com base na Tabela 8, a um nível de significância de 5\%, a variável "investimento ambiental" (INVEST) encontra-se correlacionada moderada e positivamente com as variáveis "país" (IDH), resultado correlato ao de Bufoni (2009). Enquanto que com significância de 1\% INVEST, também está relacionada positivamente com 0 impacto ambiental, conclusão preconizada nas análises anteriores e convergente com os resultados de Machado et al. (2006) e Barcellos, Oliveira e Carvalho (2009). Com relação à variável "divulgação", o investimento ambiental também se mostrou correlacionado, positivamente, à prática de disclosure total e essencial das empresas. Marques et al. (2010) apontou em seu estudo que o nível de divulgação de informações ambientais cresceu, acompanhando os montantes investidos no escopo ambiental.

Esses resultados sugerem que os investimentos ambientais realizados pelas empresas crescem à medida que é maior a qualidade de vida do país, resultado coerente. $O$ alto impacto ambiental parece demandar maiores investimentos, como demostrado. Pode-se deduzir que melhores condições de bem-estar social e ambiental têm como precursor maiores níveis de investimento com as questões ambientais. Da mesma forma, segundo as teorias da disclosure e dos stakeholders, pertencer a um setor econômico de alto impacto ambiental pressupõe maior visibilidade na sociedade, que começa a cobrar por ações que a certifiquem da conscientização das empresas.

A variável "divulgação ambiental" foi segmentada em total (DISC_T) e essencial (DISC_E). Com suporte das evidências descritas na Tabela 8, a variável DISC_T apresentou correlação fraca e negativa a um nível de significância de $10 \%$ com o país (IDH). Esse resultado demonstra um contraste, porque a melhoria da 
qualidade de vida nos países do BRICS parece requerer maiores níveis de investimento ambiental, mas não de divulgação. A variável DISC_E também se correlacionou negativamente com o IDH, porém a um nível de significância de 1\%, reforçando a relação. Ela ainda obteve correlação fraca, mas positiva, com $1 \%$ de significância, com a variável "impacto ambiental".

Ao que parece, a qualidade de vida do país não necessariamente associa-se ao nível de divulgação efetuado pelas empresas. Efetivamente, 0 investimento é a materialização das ações de responsabilidade ambiental. Nos países com IDH inferior, no contexto do BRICS, a preocupação maior pode ser com a divulgação, instrumento auxiliador na tomada de decisão do stakeholder, que pode ser utilizada para viabilizar a captação de recursos internacionais nas economias emergentes. Devido às pressões sociais, o impacto ambiental pode sim ser um fator determinante da divulgação, inclusive aquela de caráter adicional, como fora demonstrado. Deve-se, ainda, lembrar que o custo da informação divulgada é considerado pelos países. Assim sendo, o custo adicional da disclosure, para além do investimento ambiental, pode ser decisivo nas relações expostas.

Há de se ressaltar que, mesmo com as considerações extraídas da análise de correlação, estas são restritas a como as variáveis estão relacionadas, sinalizando possíveis interações. Uma verificação mais profunda é obtida por meio da regressão linear múltipla, em que se investiga o efeito influência de determinadas medidas independentes em outra dependente. Nesta pesquisa, pressupõe-se que 0 investimento ambiental (variável Dummy) é capaz de explicar a divulgação ambiental, total e essencial, das empresas. Assim como o investimento ambiental, tomou-se a variável "impacto ambiental" (IMP) também como Dummy (1 para empresas de alto impacto e 0 para empresas de médio e baixo impacto). Os resultados desta análise que testam a hipótese H1b (ver introdução) são demonstrados na Tabela 9, como segue.

Tabela 9 - Resultados da regressão linear múltipla para os modelos 1 e 2

\begin{tabular}{|c|c|c|c|c|c|c|c|c|}
\hline \multirow{2}{*}{$\begin{array}{c}\text { Variáveis } \\
\text { independentes }\end{array}$} & \multicolumn{4}{|c|}{ Modelo 1 (disclosure total) } & \multicolumn{4}{|c|}{ Modelo 2 (disclosure essencial) } \\
\hline & B & $t$ & Sig. & VIF & B & $t$ & Sig. & VIF \\
\hline Constante & 0,771 & 2,738 & $0,008^{\star * *}$ & - & 1,085 & 3,427 & $0,001^{* * *}$ & - \\
\hline INVEST & 0,324 & 6,011 & $0,000^{\star \star \star}$ & 1,041 & 0,235 & 3,880 & $0,000^{\star \star \star}$ & 1,041 \\
\hline IDH & $-1,097$ & $-3,011$ & $0,004^{* * *}$ & 1,027 & $-1,519$ & $-3,707$ & $0,000^{\star \star *}$ & 1,027 \\
\hline IMP & 0,081 & 1,495 & 0,139 & 1,041 & 0,107 & 1,746 & $0,085^{*}$ & 1,041 \\
\hline TAM & 0,016 & 1,962 & $0,053^{*}$ & 1,028 & 0,019 & 2,080 & $0,041^{* *}$ & 1,028 \\
\hline $\mathbf{R}$ & 0,645 & & & 2,139 & $\mathbf{R}$ & 0,571 & $\begin{array}{l}\text { Durbin- } \\
\text { Watson }\end{array}$ & 2,024 \\
\hline $\mathbf{R}^{2}$ & 0,416 & & $\bar{F}$ & 13,711 & $\mathbf{R}^{2}$ & 0,327 & $\mathbf{F}$ & 9,333 \\
\hline$R^{2}$ ajustado & 0,386 & & ig. & $0,000^{* * *}$ & $R^{2}$ ajustado & 0,292 & Sig. & $0,000^{\star \star *}$ \\
\hline
\end{tabular}

Nota: ${ }^{* *}$ Significante a 0,$01 ;{ }^{* *}$ Significante a 0,$05 ;{ }^{*}$ Significante a 0,10 .

Fonte: Dados da pesquisa.

Para se fazer inferências acerca da regressão linear múltipla, é necessário que o modelo obedeça a quatro pressupostos: autocorrelação, multicolinearidade, homocedasticidade e normalidade dos resíduos. Foi verificado que há ausência de autocorrelação devido ao Durbin-Watson ser próximo a 2 (2,139 e 2,024). Quanto à multicolinearidade, o estudo mostrou não haver, já que os VIF - fator de inflação de variância - estão entre $1 \mathrm{e}$ 2 para a heterocedasticidade. Por meio do modelo de regressão dos preditos padronizados pelos resíduos padronizados não significantes (sig. $=0,305$ ), verificou-se haver homocedasticidade. Por fim, os resíduos mostraram normais por meio do teste Kolmogorov-Smirnov (sig. $=0,200$ ), sendo assim, foram confirmados os pressupostos da regressão. Desse modo, verifica-se que os modelos são válidos quando apresentaram significância de $1 \%$.

O modelo 1, que trata do disclosure ambiental total, possui um poder explicativo de $38,6 \%$. A partir deste, observou-se que somente a variável "impacto ambiental" do setor (IMP) não se mostrou significante,

Revista Alcance - Eletrônica - vol. 22 - n. 4 - out./dez. 2015 
sendo que investimentos ambientais (INVEST) e tamanho (TAM) apresentaram relação positiva e o país (IDH) demonstrou relação negativa com o disclosure ambiental total. Portanto, pode-se inferir que empresas grandes que possuem investimentos ambientais e de países como a Índia, a África do Sul, e a China, com menor IDH, possuem maior disclosure ambiental total.

O modelo 2, que se dedica ao disclosure ambiental essencial, possui um poder explicativo de $29,2 \%$ e, a partir deste, observou-se que todas as variáveis apresentaram significância, em que somente o país (IDH) apresentou relação negativa com o disclosure ambiental essencial. Portanto, pode-se inferir que empresas grandes de setores de alto impacto ambiental que possuem investimentos ambientais e de países com baixo IDH possuem maior disclosure ambiental essencial.

Os resultados dos dois modelos mostraram-se semelhantes, somente a variável "impacto ambiental" do setor que foi divergente. Verificou-se, também, que os resultados da regressão confirmaram alguns achados da correlação, no caso, a relação entre o disclosure ambiental (total e essencial) e 0 investimento ambiental e 0 país. Conforme demonstrado na literatura (BRAGA; OLIVEIRA; SALOTTI, 2009; ISMAIL; IBRAHIM, 2009; GAMERSCHLAG; MÖLLER; VERBEETEN, 2010; ROVER et al., 2012), o tamanho é uma variável que explica a divulgação ambiental, sendo que essa divulgação aumenta de acordo com o tamanho da empresa, pois essa literatura adverte que as empresas grandes estão sujeitas a uma maior pressão dos stakeholders, já que a sua atuação no mercado tem uma maior percepção por parte destes. Assim como os achados de Gomes et al. (2012), a variável país demonstrou relação significante negativa com a evidenciação ambiental, logo, países que possuem uma baixo nível de qualidade de vida estão mais preocupados em demonstrar como são realizadas as suas atividades no cariz ambiental. Confirmando os achados de Braga, Oliveira e Salotti (2009) e Gamerschlag, Möller e Verbeeten (2010), o setor de atuação das empresas impacta na divulgação ambiental, no caso, o disclosure ambiental essencial, sendo que empresas de setores de alto impacto ambiental são mais perceptíveis pelos stakeholders devido à intensidade de suas atividades, exigindo destas uma maior divulgação ambiental.

Por fim, quanto aos investimentos ambientais, semelhante aos resultados de Marques et al. (2010), estes acompanham o nível da evidenciação ambiental, demonstrando que as empresas praticantes da atividade ambiental possuem o interesse de divulgar aos seus diversos stakeholders as suas ações, para assim, receber 0 reconhecimento destes. Destarte, o estudo confirmou a H1b, cujo nível de evidenciação de informações voluntárias de caráter ambiental praticado é explicado pelo investimento ambiental das empresas de capital aberto do BRICS.

\section{CONSIDERAÇÕES FINAIS}

Esta pesquisa encontrou como motivação à sua realização a relevância adquirida pela discussão acerca da responsabilidade ambiental das empresas, tanto na seara acadêmica quanto na corporativa. 0 stakeholder, cada vez mais preocupado com as ações desenvolvidas pela empresa nesse campo, ainda em construção, pressiona as organizações por informações necessárias à tomada de decisão. Esse debate ganha ainda mais força quando referido ao grupo de economias emergentes do BRICS (Brasil, Rússia, Índia, China e África do Sul). Em meio a essa reflexão, o presente estudo teve como objetivo geral determinar a relação entre o nivel de evidenciação de informações voluntárias ambientais e o investimento ambiental nas empresas de capital aberto do BRICS, a partir da construção das hipóteses H1a e H1b, testadas na pesquisa.

Inicialmente, traçado o perfil da amostra, verificou-se que as empresas estão incluídas, em sua maioria, em setores de alto ou médio impacto ambiental, aproximadamente $86 \%$ da amostra. Quanto à distribuição numérica, o Brasil predominou com a maior quantidade de empresas (25); enquanto a China, com participação tímida, teve apenas seis empresas. Quanto ao tamanho das empresas, inferido por meio do faturamento bruto das instituições, a Rússia superava sobremaneira os demais países em relação a este quesito. Por outro lado, a África do Sul apresentou a menor média de faturamento. Observou-se elevada dispersão nos valores coletados para tamanho e investimento ambiental.

Os resultados obtidos possibilitaram verificar, quanto ao nível de evidenciação ambiental no BRICS, que as empresas pertencentes ao BRICS apresentaram um nível de evidenciação total de $59 \%$, e essencial de $66 \%$, sendo a Índia o país que apresentou os maiores níveis de evidenciação total e essencial, seguida do Brasil, da China, da África do Sul e da Rússia. Observa-se, ainda, que o setor de alto impacto mostrou o maior nível de evidenciação total e essencial, e que as empresas maiores ( $3^{\circ}$ quartil e $4^{\circ}$ quartil) apresentaram o maior nível de evidenciação ambiental total e essencial. Pode-se inferir por meio dos achados, quanto ao investimento ambiental no BRICS, que o nível de evidenciação de investimentos ambientais das empresas dos componentes 
do BRICS foi de $51 \%$, em que a Índia apresentou o maior nível de divulgação e a China o menor nível de evidenciação. Observa-se ainda que as empresas de setores de alto impacto ambiental apresentaram maiores níveis de evidenciação de investimentos ambientais, e que o nível de investimento ambiental das empresas quanto ao tamanho não se pode inferir relação. Considera-se que o número de firmas pode ter algum reflexo nos resultados, com proporções distintas entre os países.

Com a realização do teste diferença de médias, o que se observou foi a sinalização de uma relação provável entre o nível de divulgação ambiental e o investimento ambiental realizado pelas empresas do BRICS. O disclosure total e o essencial, segundo a GRI, tinha média bastante superior no grupo de empresas possuidor de investimento ambiental quando confrontado ao grupo de empresas sem este investimento. Até aqui, a hipótese $\mathrm{H} 1$ não havia sido rejeitada, fazendo emergir a pressuposição de interação entre as duas variáveis. Nestes países, maiores investimentos poderiam estar relacionados a melhores níveis de divulgação, relação esta ratificada na análise de correlação. Observou-se ainda que, ao contrário daquilo que se espera, o IDH dos países mostrou-se relacionado negativamente com a divulgação. Essa inferência trouxe à tona algumas reflexões: melhor qualidade de vida implica maiores investimentos, porém, não necessariamente na divulgação ambiental? Nos países com menor IDH haveria maior preocupação com a divulgação das informações ambientais, já que elas subsidiam o stakeholder? Existe algum efeito do custo da informação gerada na sua divulgação, já que este é adicional em relação aos investimentos ambientais?

Considerando o efeito influência, o investimento ambiental mostrou-se impactante, positivamente, no nível de divulgação ambiental (total e essencial) do BRICS, ocorrendo o mesmo com o tamanho (modelo 1) e com impacto ambiental e tamanho (modelo 2). De fato, empresas maiores, portanto, com mais visibilidade ante os stakeholders, além de terem suas atividades operacionais classificadas como de alto impacto, tendem a divulgar mais, argumento amplamente defendido na literatura. Assim, também não se rejeita a hipótese $\mathrm{H} 1 \mathrm{~b}$, proposta na pesquisa, consolidando a análise sugerida no estudo, sendo, portanto, atingido o objetivo geral estabelecido.

Em alusão às limitações da pesquisa, que podem ser transformadas em novos rumos de investigação, enumera-se, inicialmente, a necessidade de realização de uma análise longitudinal, a fim de ser verificada a persistência dos resultados. Comenta-se ainda sobre a possibilidade de ampliação da amostra, pois se trabalhou apenas com as companhias de capital aberto. Se por um lado buscou-se o exame de empresas com maior visibilidade e cobrança no mercado (companhias abertas); por outro houve a limitação da não inclusão de firmas de capital fechado, com menores exigências, inclusive normativas, de divulgação. Certamente esse critério impactou o número de elementos componentes da amostra do estudo. Demais variáveis também podem ser adicionadas ao estudo, tais como o tipo de empresa e desempenho financeiro, possíveis determinantes da divulgação ambiental e da realização de investimentos ambientais. Outra sugestão refere-se à análise comparativa das relações exploradas na pesquisa, confrontando países desenvolvidos e em desenvolvimento. Por último, uma pesquisa que descrevesse a tipologia dos investimentos ambientais também seria outra sugestão de estudo aplicado a este escopo. Além do montante, que áreas mais demandam recursos, para as empresas? Espera-se que esta pesquisa tenha contribuído com a discussão que engloba a temática ambiental no meio corporativo, em especial, no tocante à evidenciação de práticas ambientais e à divulgação de investimentos ambientais, aqui, pontualmente, com relação ao BRICS.

\section{REFERÊNCIAS}

ABREU, M. C. S.; FERNANDES, J. S.; SOARES, F. A.; SILVA FILHO, J. C. L. Evolução da conduta ambiental de empresas siderúrgicas brasileiras sob a ótica dos relatórios de evidenciação ambiental. Revista Universo Contábil, v. 4, n. 4, p. 57-76, 2008.

ALON, I.; LATTEMANN, C.; FETSCHERI, M.; Li, S.; SCHNEIDER, A. M. Usage of public corporate communications of social responsibility in Brazil, Russia, India and China (BRIC). International Journal of Emerging Markets, v. 5, n. 1, p. 6-22, 2010.

BARCELLOS, F. C.; OLIVEIRA, J. C.; CARVALHO, P. G. M. Investimento ambiental em indústrias sujas e intensivas em recursos naturais e energia. Revista Iberoamericana de Economía Ecológica, v. 12, p. 33-50, 2009.

BRAGA, J. P.; OLIVEIRA, J. R. S.; SALOTTI, B. M. Determinantes do nível de divulgação ambiental nas demonstrações contábeis de empresas brasileiras. Revista de Contabilidade da Universidade Federal da Bahia, v.3, n.3, 2009.

Revista Alcance - Eletrônica - vol. 22 - n. 4 - out./dez. 2015 
BUFONI, A. L. A relação entre performance financeira e ambiental nos países em desenvolvimento: 0 caso do Brasil. Sociedade, Contabilidade e Gestão, v. 4, n. 2, p. 38-57, 2009.

CALIXTO, L. Uma análise da evidenciação ambiental de companhias brasileiras - de 1997 a 2005. UnB Contábil, v. 10, n. 1, p. 9-37, 2007.

COLARES, A. C. V.; LAMOUNIER, W. M.; BRESSAN, V. G. F.; BORGES, D. L. O balanço social como indicativo socioambiental das empresas do índice de sustentabilidade empresarial da BM\&FBovespa, Revista de

Contabilidade do Mestrado em Ciências Contábeis da UERJ, v. 17, Edição Especial, p. 83-100, 2012.

COLLIS, J.; HUSSEY, R. Pesquisa em administração: um guia prático para alunos de graduação e pósgraduação. 2 ed. Porto Alegre: Bookman, 2005.

DANTAS, J. A.; ZENDERSKY, H. C.; NIYAMA, J. K. A dualidade entre os benefícios do disclosure e a relutância das organizações em aumentar o grau de evidenciação. In: ENCONTRO NACIONAL DE PESQUISA EM ADMINISTRAÇÃO, EnANPAD, 2004; Curitiba, Anais... Curitiba, 2004.

DE LUCA, M. M. M.; MOURA, A. A. F.; NASCIMENTO, F. S. P. Evidenciação voluntária de informações sociais por empresas de capital aberto no Brasil com base nos indicadores de responsabilidade social da ONU. Revista Alcance, v. 19, n. 03, p. 362-380, 2012.

DONALDSON, T.; PRESTON, L. E. The stakeholder theory of the corporation: Concepts, evidence, and implications. The Academy of Management Review, v. 20, n. 1, p. 65-91, 1995.

DYE, R. An evaluation of "essays on disclosure" and the disclosure literature in accounting. Journal of Accounting and Economics, v.32, n.1-3, p.181-235, dec. 2001.

FÁVERO, L. P.; BELFIORE, P.; SILVA F. L.; CHAN, B. L. Análise de dados: modelagem multivariada para tomada de decisões. 4. ed. Rio de Janeiro: Elsevier, 2009.

FREEMAN, R. E. Strategic Management: a stakeholder approach. Boston: Pitmann, 1984.

FREEMAN, E.; HARRISON, J.; WICKS, A. Managing for stakeholders: survival, reputation, and success. New Haven and London: Yale University Press, 2007.

FREEMAN, R. E.; WICKS, A. C.; PARMAR, B. Stakeholder theory and the corporate objective revisited.

Organization Science, v. 15, n. 3, p. 364-369, 2004.

FTSE4GOOD INDEX SERIES. 2010. Inclusion Criteria. Disponível:

$<$ http://www.ftse.com/Indices/FTSE4Good_Index_Series/Downloads/F4G_Criteria.pdf>. Acesso em: 09 jun. 2013.

FREITAS, D. P. S.; QUARESMA, J. C. C.; SCHMITT, S. R. Z.; GONÇALVES, T. L.; QUINTANA, A. C. Contabilidade ambiental: um estudo bibliométrico em revistas científicas brasileiras. Revista Ambiente Contábil, v. 4, n. 1, p. 72-88, 2012.

FRIEDMAN, M. The social responsibility of business is to increase its profits. The New York Times Magazine, $v$. 13, p. 122-126, set. 1970.

FONSECA, F. A. P. B.; ALMEIDA, K. K. N.; FRANÇA, R. D. Evidenciação de informações ambientais em empresas do segmento de utilidade pública listadas na BM\&FBovespa: um estudo sobre a evolução na divulgação dessas informações. Revista de Administração, Contabilidade e Sustentabilidade, v. 2, n. 3, p. 51-68, 2012.

GAMERSCHLAG, R.; MÖLLER, K.; VERBEETEN, F. Determinants of voluntary CSR disclosure: empirical evidence from Germany. Review of Managerial Science. v. 10, p. 10-52, 2010.

GOMES, P. H. V.; DE LUCA, M. M. M.; CARDOSO, V. I. C.; PONTE, V. M. R. Fatores determinantes do disclosure voluntário sob o enfoque da sustentabilidade: uma análise das empresas dos países do BRIC. In: XIV Encontro Nacional sobre Gestão Empresarial e Meio Ambiente - ENGEMA, 2012, São Paulo. Anais... XIV ENGEMA. São Paulo, 2012.

HAIR, J. F., JR.; BLACK, W. C.; BABIN, B. J.; ANDERSON, R. E.; TATHAN, R. L. Análise multivariada de dados. 6. ed. Porto alegre: Bookman, 2009.

IFRS. IAS 21 - The effects of changes in foreign exchange rates, dez. 2003. Disponível em: $<h t t p: / / w w w$. ifrs.org/Documents/IAS21.pdf>. Acesso em: 9 jun. 2013.

Alan Diogenes Gois, José Glauber C. dos Santos, Augusto Cezar de Aquino Cabral e Maria Naíula M. Pessoa 
ISMAIL, K. N. I. K.; IBRAHIM, A. H. Social and environmental disclosure in the annual reports of Jordanian companies. Issues in Social and Environmental Accounting, v. 2, n. 2, p. 198-210, dec. 2008/jan. 2009.

LU, Y.; ABEYSEKERA, I. Stakeholders' power, corporate characteristics, and social and environmental disclosure: evidence from China. Journal of Cleaner Production, v. 64, p. 426-436, 2014.

MACHADO, R. T. M.; BERNARDO, D. C. R.; PEREIRA, N. C.; PESSANHA, G. R. G. Investimentos Ambientais e Sociais Externos: um estudo comparativo das companhias de capital aberto no Brasil. In: XXX ENCONTRO NACIONAL DE PESQUISA EM ADMINISTRAÇÃO, EnANPAD, 2006, Salvador, Anais... XXX EnANPAD, Salvador, 2006.

MACHADO, M. A. V.; MACEDO, M. A. S.; MACHADO, M. R.; SIQUEIRA, J. R. M. Análise da relação entre investimentos socioambientais e a inclusão de empresas no índice de sustentabilidade empresarial (ISE) da BM\&FBovespa. Revista de Ciências da Administração, v. 14, n. 32, p. 141-156, 2012.

MACHADO, M. R.; MACHADO, M. A. V.; SANTOS, A. A relação entre setor econômico e investimentos sociais e ambientais. UnB Contábil (Cessou em 2007. Cont. ISSN 1984-3925 Contabilidade, Gestão e Governança), v. 13, p. 102-115, 2010.

MARQUES, M. M.; BARRETO JUNIOR, E. A. M.; FREIRE, F. S.; PEREIRA, E. M. Evidenciação ambiental: uma análise da evolução dos investimentos ambientais e o reflexo no que é divulgado. In: $10^{\circ}$ Congresso USP Controladoria e Contabilidade, 2010, São Paulo. Anais... Congresso USP. São Paulo: USP, 2010.

MARTINS, G. A.; THEÓPHILO, C. R. Metodologia da investigação científica para ciências sociais aplicadas. São Paulo: Atlas, 2009.

PINHO, D. R.; DE LUCA, M. M. M.; SANTOS, S. M.; OLIVEIRA, M. C.; OLIVEIRA, B. C. Responsabilidade social corporativa: um estudo sobre o comportamento das distribuidoras de energia elétrica da região nordeste.

Revista Alcance, v. 14, n. 1, p. 69-88, 2007.

RAUPP, F. M.; CORREIA, C. L.; FEY, V. A. Gastos ambientais no ramo de geração e distribuição de energia elétrica. Revista de Contabilidade do Mestrado em Ciências Contábeis da UERJ, v. 14, n.3, p. 14-26, 2009.

RIBEIRO, A. M. Evidenciação ambiental: uma investigação transnacional dos reflexos de diferentes marcos regulatórios sobre as práticas de evidenciação ambiental das empresas do setor de petróleo e gás natural. 2009. 224 f. Dissertação (Mestrado em Ciências Contábeis). Programa de Pós-Graduação em Contabilidade, Universidade Federal de Santa Catarina (UFSC), Florianópolis, 2009.

RIBEIRO, A. M.; NASCIMENTO, L. F.; BELLEN, H. M. V. Evidenciação ambiental: análise comparativa multissetorial entre Brasil, Estados Unidos e Inglaterra. Revista Contemporânea de Economia e Gestão, v. 7, n. 1, p. 7-22, 2009.

ROSA, F. S.; VOSS, B. L.; ENSSLIN, S. R.; FELIU, V. R. Evidenciação ambiental: estudo comparativo das contribuições teórico-metodológicas de Brasil e Espanha. Revista Universo Contábil, v. 8, n. 1, p. 123-140, 2012.

ROVER, S.; TOMAZZIA, E. C.; MURCIA, F. D.; BORBA, J. A. Explicações para a divulgação voluntária ambiental no Brasil utilizando a análise de regressão em painel. Revista de Administração, v.47, n.2, p.217230, abr./maio/jun. 2012.

SALOTTI, B.; YAMAMOTO, M. Ensaio sobre a teoria da divulgação. Brazilian Business Review, Vitória, v.2, n.1, p.53-70, jan.jjun. 2005.

SUTTIPUN, M.; STANTON, P. A study of environmental disclosures by Thai listed companies on websites. Procedia Economics and Finance. v. 2, p. 9-15, 2012.

SAMPIERI, R. H.; COLLADO, C. F.; LUCIO, P. B. Metodologia de pesquisa. 3 ed., São Paulo: McGraw Hill, 2013.

SOUZA, J. A.; COSTA, T. M. T. Responsabilidade social empresarial e desenvolvimento sustentável: conceitos, práticas e desafios para a contabilidade. Organizações em Contexto, v. 8, n. 15, p. 213-238, 2012.

VELLANI, C. L.; NAKAO, S. H. Investimentos ambientais e redução de custos. Revista de Administração da UNIMEP, v. 7, n. 2, p. 57-75, 2009. 
VERRECCHIA, R. Essays on disclosure. Journal of Accounting and Economics, v.32, n.1-3, p.97-180, dec. 2001.

VIEIRA, F. V.; VERÍSSIMO, M. P. Crescimento econômico em economias emergentes selecionadas: Brasil, Rússia, Índia, China (BRIC) e África do Sul. Revista Economia e Sociedade, Campinas, v. 18, n. 3 (37), p. 513546, dez.2009. 